\title{
Association of Initial Trough Concentrations of Vancomycin with Outcomes in Pediatric Patients with Gram-Positive Bacterial Infection
}

\author{
Miko Kondo, ${ }^{a}$ Shunsaku Nakagawa, ${ }^{* a}$ Satoru Orii, ${ }^{a}$ Kotaro Itohara,${ }^{a}$ Mitsuhiro Sugimoto, ${ }^{a}$ \\ Tomohiro Omura, ${ }^{b}$ Yuki Sato, ${ }^{a}$ Satoshi Imai, ${ }^{a}$ Atsushi Yonezawa, ${ }^{a, c}$ Takayuki Nakagawa, ${ }^{a}$ and \\ Kazuo Matsubara ${ }^{a}$ \\ ${ }^{a}$ Department of Clinical Pharmacology and Therapeutics, Kyoto University Hospital; 54 Kawaharacho, Shogoin, \\ Sakyo-ku, Kyoto 606-8507, Japan: ${ }^{b}$ Department of Pharmacy, Kobe University Hospital; 7-5-2 Kusunoki-cho, \\ Chuo-ku, Kobe 650-0017, Japan: and ${ }^{c}$ Graduate School of Pharmaceutical Sciences, Kyoto University; \\ 54 Kawaharacho, Shogoin, Sakyo-ku, Kyoto 606-8507, Japan.
}

Received November 13, 2019; accepted July 14, 2020

Vancomycin is a glycopeptide antibiotic used for the treatment of Gram-positive infections. For adult patients, treatment with vancomycin requires effective therapeutic drug-monitoring (TDM) to achieve clinical outcomes and reduce the incidence of adverse effects. However, it remains still unclear whether the TDM with vancomycin is beneficial in yielding better clinical outcomes in pediatrics. The objective of our study was to evaluate whether the clinical response to treatment was associated with initial trough concentrations of vancomycin in pediatric patients. A retrospective observation study of 60 patients (age: 1 month-15 years) who had completed and qualified for analysis was conducted at Kyoto University Hospital. The response to treatment was assessed by the time to resolution of fever and time to $50 \%$ decline in $\mathrm{C}$-reactive protein (CRP). In addition, we explored whether vancomycin trough level was associated with the baseline characteristics. Trend analysis showed that there were significant correlations between vancomycin trough level and age, body weight, estimated glomerular filtration rate, and serum albumin levels. The time to resolution of fever of the patients with higher initial trough level $(\geq 5 \mu \mathrm{g} / \mathrm{mL})$ was significantly lower than that of the patients with lower trough level $(<5 \mu \mathrm{g} / \mathrm{mL})$. The higher vancomycin concentration tended to be associated with the shorter time to $50 \%$ decline in CRP. The findings suggest that initial trough concentration is important in achieving better outcomes with vancomycin treatment in pediatrics.

Key words vancomycin; therapeutic drug monitoring; Gram-positive infection

\section{INTRODUCTION}

Gram-positive bacteria are a major cause of infection in children, especially patients treated with immunosuppressive therapy, total parenteral nutrition, tracheostomies, or post-surgery patients or premature infants. Vancomycin is a glycopeptide antibiotic widely used for the treatment of Gram-positive infections, including Methicillin-resistant Staphylococcus aureus (MRSA) infection. The Infectious Diseases Society of America (IDSA) has published a guideline regarding the use of vancomycin for the treatment of MRSA infections in adults and pediatrics. ${ }^{1)}$ The guideline recommends a dose of vancomycin at $15-20 \mathrm{mg} / \mathrm{kg}$ every $8-12 \mathrm{~h}$ for adult patients, and a dose of $15 \mathrm{mg} / \mathrm{kg}$ every $6 \mathrm{~h}$ for pediatrics with serious or invasive infections.

The pharmacokinetics of vancomycin is affected by several factors, such as renal function, age and serum albumin., ${ }^{2,3}$ It is well known that therapeutic drug-monitoring (TDM) of vancomycin is effective in achieving positive clinical outcomes and reducing the incidence of adverse effects in adult patients. ${ }^{4)}$ Monitoring the trough concentration is the most accurate and practical approach in guiding vancomycin dosing. ${ }^{1)}$ In pediatric patients, the incidence of acute renal injury has been associated with higher trough concentrations of vancomycin (TCV). ${ }^{5-8)}$ These findings suggest that trough concentrations-guided dosing could be useful to avoid nephrotoxicity of vancomycin in pediatrics. However, it still remains unclear whether TDM of vancomycin in pediatric patients with Grampositive infection is beneficial in achieving useful clinical outcomes. Previous studies have reported that clinical outcomes in children with higher TCV $(>10 \mu \mathrm{g} / \mathrm{mL})$ do not significantly differ from those in patients with lower TCV $(\leq 10 \mu \mathrm{g} / \mathrm{mL}) .^{9-11)}$ The IDSA guideline recommends TCV of $>10 \mu \mathrm{g} / \mathrm{mL}$ in pediatric patients, and $15-20 \mu \mathrm{g} / \mathrm{mL}$ for invasive infections, which are levels adjusted equivalent to those of adults. However, these recommendations on TCV are based mainly on data from adult patients or limited data from children. As for the correlation between dosage and TCV in pediatrics, vancomycin at the dosage of $70 \mathrm{mg} / \mathrm{kg} / \mathrm{d}$ would be required to provide a trough concentration of $10 \mu \mathrm{g} / \mathrm{mL} .^{12,13)}$ Thus, when pediatric patients are administered with the empiric dosage or standard dosage of vancomycin recommended in the IDSA guideline, the TCV is more likely to be $<10 \mu \mathrm{g} / \mathrm{mL}$ in most cases. Taken together, it suggests that the target level of vancomycin exposure for adult patients is not applicable to pediatric patients.

Based on this background, the cut-point for the target TCV in pediatrics could be $<10 \mu \mathrm{g} / \mathrm{mL}$. In this study, we evaluated whether the clinical response to treatment with vancomycin was associated with the TCV in pediatric patients. For this purpose, we conducted a retrospective case-control study, and also examined the effect of patients' characteristics on TCV. 


\section{MATERIALS AND METHODS}

Study Design and Patients This was a retrospective case-control study conducted at Kyoto University Hospital. This study was designed in accordance with the Declaration of Helsinki and was approved by the Medical Ethics Committee of Kyoto University Graduate School and Faculty of Medicine (No. E2461). Patients were eligible for enrollment if they were administered with vancomycin from April 2005 to March 2014, and their ages were from 1 month to 15 year. Then, the patients were excluded from the analysis if they did not receive vancomycin for more than $48 \mathrm{~h}$, or the concentration of vancomycin was not available. In evaluating the effect of trough values of vancomycin on clinical response, patients were further excluded if Gram-positive bacteria were not detected from the any culture test (Fig. 1).

Definition Concentrations of vancomycin were measured by a fluorescence polarization immunoassay (FPIA) using a TDxFLx $^{\circledR}$ analyzer (Abbott Japan, Tokyo, Japan) or a particleenhanced turbidimetric inhibition immunoassay (PETINIA) using Dmension ${ }^{\circledR}$ system (Siemens, Tokyo, Japan). The TCV was defined as the serum vancomycin concentration obtained after at least the third dose and within $30 \mathrm{~min}$ of the next scheduled dose. "Day 1" was defined as the first day when vancomycin was administered for the first time. The initial TCV was defined as the trough concentration observed at day 3. The average TCV was calculated as the average value during the treatment period.

The clinical outcome was the time to resolution of fever ${ }^{14)}$ and the time to $50 \%$ decline in C-reactive protein $(\mathrm{CRP}){ }^{10)}$
The duration of fever was defined as the number of calendar days in hospital with a recorded body temperature of $37.5^{\circ} \mathrm{C}$. The time to $50 \%$ decline in CRP was defined as the number of calendar days until a $>50 \%$ decrease in CRP compared with the value obtained at the last time before the start of vancomycin therapy. We also assessed all-cause mortality within $30 \mathrm{~d}$ of index blood culture.

Additionally, the age, sex, body weight, site of infection, regimen of vancomycin therapy, comorbidity, laboratory data (serum albumin, serum creatinine and minimum inhibitory concentration (MIC) of vancomycin), and concomitant use of antibiotics, were obtained from the medical charts. Estimated glomerular filtration rate (eGFR) of each patient was calculated according to a previous report. ${ }^{15,16)}$ The MIC of vancomycin was determined using a Microscan WalkAway plus System (Beckman Coulter, Japan) and MicroScan Pos Series (Beckman Coulter).

Statistical Analysis We divided patients into 2 groups: patients with lower TCV $(<5 \mu \mathrm{g} / \mathrm{mL})$ and patients with higher TCV ( $\geq 5 \mu \mathrm{g} / \mathrm{mL}$ ). The differences (with $95 \%$ confidence intervals (CI)) in clinical outcomes between these 2 groups were estimated by logistic regression. Multivariate regression analysis was used to determine estimates adjusted for the effects of bacterium, bacterial culture, and MIC of vancomycin.

Data are expressed as the median with ranges for continuous variables, and numbers (\%) for categorical variables. Relationships between the degree of vancomycin concentrations and patients' demographics or clinical characteristics were analyzed using the Jonckheere-Terpstra test, Student's $t$-test, or Welch's test for continuous variables, and the Cochran-



Fig. 1. Participant Flow Diagram

A total of 102 patients were enrolled in this study. Then, 42 patients were excluded, and 60 pediatric patients were subjected to analyses of factors that had affected TCV. The reasons for exclusion were as follows: no administration of vancomycin for more than $48 \mathrm{~h}(n=24)$, no measurement of serum vancomycin concentration $(n=4)$, loss of information about the accurate dosing period $(n=14)$. Thereafter, we evaluated whether the response to vancomycin therapy was associated with TCV in pediatric patients. For this purpose, we further excluded 30 patients from the subsequent analysis, since infection with Gram-positive bacteria were not detected in these patients. 
Armitage test or Fisher's exact test for categorical variables. The correlation between initial or average TCV and the clinical response was analyzed using the multiple comparisons with Dunn's two-tailed test. We considered differences where $p<0.05$ to be statistically significant. All analyses were done using JMP software (version 14.0, SAS Institute Inc., Cary, NC, U.S.A.).

\section{RESULTS}

A total of 102 patients were enrolled in this study, and 42 patients were excluded from the analyses (Fig. 1). The reasons for exclusion were as follows: no administration of vancomycin for more than $48 \mathrm{~h}(n=24)$, no measurement of serum vancomycin concentration $(n=4)$, loss of information about the accurate dosing period $(n=14)$. Thus, 60 pediatric patients were subjected to analyses of factors that had affected TCV. Based on the demographics or clinical characteristics of 60 patients (Table 1), the initial TCV were as follows: $<5 \mu \mathrm{g} / \mathrm{mL}$ in 28 patients $(46.7 \%), 5-<10 \mu \mathrm{g} / \mathrm{mL}$ in 16 patients $(26.7 \%)$, $10-<15 \mu \mathrm{g} / \mathrm{mL}$ in 9 patients $(15.0 \%)$, and $\geq 15 \mu \mathrm{g} / \mathrm{mL}$ in 7 patients $(11.7 \%)$. Based on the initial TCV, we divided patients' characteristics into 3 groups: those with initial TCV of $<5$,
$5-<10$, and $\geq 10 \mu \mathrm{g} / \mathrm{mL}$ (Table 2 ). The correlations between the initial TCV and the age, sex, body weight, serum creatinine, eGFR, serum albumin, vancomycin dosing regimen (dosage and interval) and comorbidities were assessed. The trend analysis showed that there were statistically significant correlations between the degree of initial TCV and age, body weight, eGFR, and serum albumin.

Thereafter, we evaluated whether the response to vancomycin therapy was associated with TCV in pediatric patients. For this purpose, we further excluded 30 patients from the subsequent analysis, since Gram-positive bacteria were not detected from any site of culture in these patients (Fig. 1). There was a significant difference in the time to resolution of fever between patients with initial TCV of $<5$ and $\geq 10 \mu \mathrm{g} / \mathrm{mL}$, but not between patients with initial TCV of $<5-10$ and $\geq 10 \mu \mathrm{g} / \mathrm{mL}$ (Table 3); therefore, we divided patients into 2 groups: patients with lower TCV $(<5 \mu \mathrm{g} / \mathrm{mL})$ and patients with higher TCV $(\geq 5 \mu \mathrm{g} / \mathrm{mL}$ ). The characteristics of patients included in the analysis on the clinical outcomes are shown in Table 4. The effects of TCV on the clinical outcomes were examined with logistic regression analysis (Table 5). The time to resolution of fever of the patients with higher TCV $(\geq 5 \mu \mathrm{g} / \mathrm{mL})$ was significantly lower than that of the patients with lower TCV

Table 1. Demographics and Characteristics of Patients

\begin{tabular}{|c|c|c|}
\hline \multicolumn{3}{|l|}{ Variables } \\
\hline \multicolumn{2}{|c|}{ Number of patients } & 60 \\
\hline \multicolumn{2}{|c|}{ Age (year; median (range)) } & $1.5(0.083-14)$ \\
\hline \multicolumn{2}{|c|}{ Sex $(n$, male/female $)$} & $32 / 28$ \\
\hline \multicolumn{2}{|c|}{ Body weight (kg; median (range)) } & $10.5(0.9-57.9)$ \\
\hline \multicolumn{2}{|c|}{ Serum creatinine (mg/dL; median (range)) } & $0.2(0.1-0.5)$ \\
\hline \multicolumn{2}{|c|}{ Estimated glomerular filtration rate (eGFR) $\left(\mathrm{mL} / \mathrm{min} / 1.73 \mathrm{~m}^{2} ;\right.$ median (range)) } & $94.6(38.5-229.3)$ \\
\hline \multicolumn{2}{|c|}{ Serum albumin $(\mathrm{g} / \mathrm{dL}$; median (range) $)$} & $3.4(2.2-5.3)$ \\
\hline \multicolumn{2}{|c|}{ Initial vancomycin dose $(\mathrm{mg} / \mathrm{kg} / \mathrm{d}$; median (range)) } & $40(18.7-150)$ \\
\hline \multicolumn{2}{|c|}{ Dosing interval $(n, 6 / 8 / 12 / 24 h)$} & $6 / 37 / 16 / 1$ \\
\hline \multirow[t]{2}{*}{ Initial TCV } & Continuous ( $\mu \mathrm{g} / \mathrm{mL}$; median (range)) & $5.3(0.8-30.8)$ \\
\hline & Categorical $(n,<5 / 5-<10 / 10-<15 / \geq 15 \mu \mathrm{g} / \mathrm{mL})$ & $28 / 16 / 9 / 7$ \\
\hline \multirow[t]{2}{*}{ Average TCV } & Continuous $(\mu \mathrm{g} / \mathrm{mL}$; median (range) $)$ & $7.9(0.9-28.8)$ \\
\hline & Categorical $(n, \quad<5 / 5-<10 / 10-<15-\geq 15 \mu \mathrm{g} / \mathrm{mL})$ & $18 / 17 / 18 / 7$ \\
\hline
\end{tabular}

Values are expressed as the median (with range) or the number of patients (n) accordingly. TCV, trough concentration of vancomycin.

Table 2. Correlations between Patients' Characteristics and Initial TCV

\begin{tabular}{|c|c|c|c|c|c|}
\hline \multirow{2}{*}{\multicolumn{2}{|c|}{ Variables }} & \multicolumn{3}{|c|}{ Initial TCV $(\mu \mathrm{g} / \mathrm{mL})$} & \multirow{2}{*}{$p$ for trenc } \\
\hline & & $<5$ & From 5 to $<10$ & $\geq 10$ & \\
\hline \multicolumn{2}{|c|}{ Number of patients } & 28 & 16 & 16 & - \\
\hline \multicolumn{2}{|l|}{ Age (year) } & $2(0.083-14)$ & $2.5(0.25-14)$ & $0.83(0.083-6)$ & 0.036 \\
\hline \multicolumn{2}{|c|}{ Sex ( $n$, male/female) } & $15 / 13$ & $8 / 8$ & $9 / 7$ & 0.901 \\
\hline \multicolumn{2}{|c|}{ Body weight (kg) } & $12.8(2.3-48)$ & $15.1(1.6-57.9)$ & $7.7(0.9-21.2)$ & 0.020 \\
\hline \multicolumn{2}{|c|}{ Serum creatinine $(\mathrm{mg} / \mathrm{dL})$} & $0.2(0.1-0.5)$ & $0.26(0.1-0.4)$ & $0.2(0.1-0.4)$ & 0.424 \\
\hline \multicolumn{2}{|c|}{ eGFR $\left(\mathrm{mL} / \mathrm{min} / 1.73 \mathrm{~m}^{2}\right)$} & $112.3(42.3-214.3)$ & $105.4(46.5-229.3)$ & $75.3(38.5-127.6)$ & 0.004 \\
\hline \multicolumn{2}{|c|}{ Serum albumin $(g / d L)$} & $3.3(2.2-4.0)$ & $3.45(2.4-4.3)$ & $3.55(2.3-5.3)$ & 0.015 \\
\hline \multicolumn{2}{|c|}{ Initial vancomycin dose $(\mathrm{mg} / \mathrm{kg} / \mathrm{d})$} & $40(18.7-70)$ & $36.5(20-60)$ & $40.5(32-150)$ & 0.432 \\
\hline \multicolumn{2}{|c|}{ Dosing interval $(n, 6 / 8 / 12 / 24 h)$} & $2 / 16 / 9 / 1$ & $2 / 10 / 4 / 0$ & $2 / 11 / 3 / 0$ & 0.432 \\
\hline \multirow[t]{3}{*}{ Comorbidity $(n)$} & Post-liver transplantation & 15 & 5 & 8 & 0.566 \\
\hline & Hematologic malignancy & 7 & 3 & 2 & \\
\hline & Congenital heart disease & 0 & 1 & 4 & \\
\hline
\end{tabular}

Values are expressed as the median (with range) or the number of patients $(n)$. Correlations between the degree of initial TCV and patients' demographics or clinical characteristics were analyzed using the Jonckheere-Terpstra test for continuous variables, and the Cochran-Armitage test for categorical variables. 
Table 3. Correlations between TCV and Clinical Response

\begin{tabular}{|c|c|c|c|}
\hline \multirow{2}{*}{ Outcome } & \multicolumn{3}{|c|}{ Initial TCV $(\mu \mathrm{g} / \mathrm{mL})$} \\
\hline & $<5(n=12)$ & From 5 to $<10(n=10)$ & $\geq 10(n=8)$ \\
\hline Time to resolution of fever $\left(<37.5^{\circ} \mathrm{C}\right)$, days & $7(1-25)^{*}$ & $3.5(1-13)$ & $2(1-7)$ \\
\hline Time to $50 \%$ decline in CPR, days & $4(2-28)$ & $3.5(2-16)$ & $4.5(2-10)$ \\
\hline \multirow{2}{*}{ Outcome } & \multicolumn{3}{|c|}{ Average TCV $(\mu \mathrm{g} / \mathrm{mL})$} \\
\hline & $<5(n=9)$ & From 5 to $<10(n=10)$ & $\geq 10(n=11)$ \\
\hline Time to resolution of fever $\left(<37.5^{\circ} \mathrm{C}\right)$, days & $4(1-25)$ & $4.5(1-17)$ & $2(1-14)$ \\
\hline Time to $50 \%$ decline in CPR, days & $4(2-28)$ & $5(2-23)$ & $4(2-16)$ \\
\hline
\end{tabular}

Data were statistically analyzed using the multiple comparisons with Dunn's two-tailed test. * $p<0.05(*)$ represents significant difference from patients with TCV $\geq 10(\mu \mathrm{g} / \mathrm{mL})$

Table 4. Characteristics of Patients Included in the Analysis on Clinical Response

\begin{tabular}{|c|c|c|c|}
\hline \multicolumn{2}{|l|}{ Variables } & Initial $\mathrm{TCV} \geq 5 \mu \mathrm{g} / \mathrm{mL}$ & Initial $\mathrm{TCV}<5 \mu \mathrm{g} / \mathrm{mL}$ \\
\hline \multicolumn{2}{|l|}{ Number of patients } & 18 & 12 \\
\hline \multicolumn{2}{|l|}{ Age (year) } & $1(0.083-14)$ & $1.5(0.33-14)$ \\
\hline \multicolumn{2}{|l|}{ Sex ( $n$, male/female $)$} & $10 / 8$ & $8 / 4$ \\
\hline \multicolumn{2}{|l|}{ Body weight (kg) } & $9.5(0.9-57.9)$ & $11.0(6.6-32.1)$ \\
\hline \multicolumn{2}{|c|}{ Serum creatinine $(\mathrm{mg} / \mathrm{dL})$} & $0.2(0.1-0.4)^{*}$ & $0.2(0.1-0.3)$ \\
\hline \multicolumn{2}{|c|}{$\mathrm{eGFR}\left(\mathrm{mL} / \mathrm{min} / 1.73 \mathrm{~m}^{2}\right)$} & $86.8(38.5-229.3)$ & $115.1(70.5-214.3)$ \\
\hline \multicolumn{2}{|c|}{ Serum albumin $(\mathrm{g} / \mathrm{dL})$} & $3.6(2.3-5.3)^{*}$ & $3.3(2.2-4.0)$ \\
\hline \multicolumn{2}{|c|}{ Initial vancomycin dose $(\mathrm{mg} / \mathrm{kg} / \mathrm{d})$} & $42(25-150)$ & $40(30-62.5)$ \\
\hline \multicolumn{2}{|c|}{ Dosing interval $(n, 6 / 8 / 12 / 24 h)$} & $3 / 11 / 4 / 0$ & $1 / 5 / 5 / 1$ \\
\hline \multicolumn{2}{|c|}{ Average TCV $(\mu \mathrm{g} / \mathrm{mL})$} & $10.9(3.9-20.5)^{* *}$ & $4.7(0.9-11.6)$ \\
\hline \multirow[t]{4}{*}{ Bacterium $(n)$} & Staphylococcus & 15 & 9 \\
\hline & Streptococcus & 2 & 1 \\
\hline & Enterococcus & 0 & 2 \\
\hline & Bacillus & 1 & 0 \\
\hline \multicolumn{2}{|c|}{$\operatorname{MIC}(n, 0.5 / 1 / 2 / 4 \mu \mathrm{g} / \mathrm{mL})$} & $2 / 8 / 6 / 2$ & $1 / 2 / 9 / 0$ \\
\hline \multirow[t]{6}{*}{ Bacterial culture $(n)$} & Blood & 9 & 3 \\
\hline & Central venous catheter & 4 & 3 \\
\hline & Cerebrospinal fluid & 0 & 1 \\
\hline & Bile & 2 & 4 \\
\hline & Sputum & 3 & 0 \\
\hline & Ascitic fluid & 0 & 1 \\
\hline \multicolumn{2}{|c|}{ Concomitant use with antibiotics: $n(\%)$} & $16(88.9)$ & $12(100.0)$ \\
\hline \multicolumn{2}{|c|}{ Concomitant use with antifungals: $n(\%)$} & $3(16.7)$ & $6(50.0)$ \\
\hline \multirow[t]{3}{*}{ Comorbidity $(n)$} & Post-liver transplantation & 7 & 10 \\
\hline & Hematologic malignancy & 3 & 1 \\
\hline & Congenital heart disease & 3 & 0 \\
\hline \multicolumn{2}{|l|}{ Neutropenia $(n)$} & 4 & 2 \\
\hline
\end{tabular}

Values are expressed as the median (with range) or the number of patients $(n)$. Neutropenia, a neutrophil count of $<0.5 \times 10^{9} / \mathrm{L}$. Differences in patients' characteristics were assessed using the Student's $t$-test or Welch's test for continuous variables, and the Fisher's exact test for categorical variables. Differences where $p<0.05(*)$ were considered statistically significant between the two groups.

$(<5 \mu \mathrm{g} / \mathrm{mL})$. After the adjustment for the effects of bacterium, bacterial culture, and MIC of vancomycin, the significant effect of TCV was detected. The higher vancomycin concentration tended to be associated with the shorter time to $50 \%$ decline in CRP, although the effect was not significant. No patients died during observation. We repeated the analyses including only patients infected with MRSA or Methicillinresistant coagulase-negative Staphylococci (MRCNS) $(n=23$; 14 patients with higher TCV, 9 patients with lower TCV). The effect of TCV on the time to resolution of fever was still significant in the unadjusted model; however, the effect was not significant in the adjusted model.

\section{DISCUSSION}

The objective of this study was to evaluate whether the TCV was associated with clinical outcome in pediatric patients with infection. The major findings in the present study were that the TCV at day 3 was associated with a shorter time to defervescence, and that serum albumin, eGFR, age and body weight were factors that affected TCV in pediatric patients.

Our analysis suggested that the initial TCV of $<5 \mu \mathrm{g} / \mathrm{mL}$ indicated the poor outcome in pediatric patients with infection. Therefore, the initial dosage of vancomycin might be important in achieving clinical response to vancomycin even in pediatrics. However, previous studies reported meagre cor- 
Table 5. Effects of TCV on Clinical Response

\begin{tabular}{|c|c|c|c|c|}
\hline Outcome & $\begin{array}{l}\text { Initial TCV } \\
\geq 5 \mu \mathrm{g} / \mathrm{mL}\end{array}$ & $\begin{array}{l}\text { Initial TCV } \\
<5 \mu \mathrm{g} / \mathrm{mL}\end{array}$ & $\begin{array}{l}\text { Crude difference } \\
\quad(95 \% \mathrm{CI})\end{array}$ & $\begin{array}{l}\text { Adjusted difference } \\
\qquad(95 \% \mathrm{CI})\end{array}$ \\
\hline \multicolumn{5}{|l|}{ Total $(n=30)$} \\
\hline Time to resolution of fever $\left(<37.5^{\circ} \mathrm{C}\right)$, days & $3(1-13)$ & $7(1-25)$ & $-5.2(-9.0 \text { to }-1.4)^{* *}$ & $-4.9(-9.4 \text { to }-0.5)^{*}$ \\
\hline Time to $50 \%$ decline in CPR, days & $4(2-16)$ & $4(2-28)$ & $-3.4(-8.1$ to 1.4$)$ & $-4.4(-9.8$ to 1.0$)$ \\
\hline \multicolumn{5}{|l|}{ Patients infected with MRSA or MRCNS $(n=23)$} \\
\hline Time to resolution of fever $\left(<37.5^{\circ} \mathrm{C}\right)$, days & $2.5(1-7)$ & $6(1-14)$ & $-3.2(-5.8 \text { to }-0.7)^{*}$ & $-2.6(-5.7$ to 0.6$)$ \\
\hline Time to $50 \%$ decline in CPR, days & $4(2-16)$ & $3(2-15)$ & $0.0(-3.6$ to 3.6$)$ & $-0.6(-5.1$ to 3.8$)$ \\
\hline
\end{tabular}

The effects of initial TCV on the clinical response were expressed as differences with $95 \%$ confidence intervals (CI), estimated by linear regression. Multivariate regression analysis was used to determine estimates adjusted for the effects of bacterium, bacterial culture, or MIC of vancomycin. Differences where $p<0.05(*)$ or $p<0.01(* *)$ were considered statistically significant.

relation between TCV and treatment outcomes in pediatric patients with MRSA or Gram-positive infection. ${ }^{9-11,17)}$ These differences may be attributable to the following reasons 1) one of the studies assessed the effect of average TCV values ${ }^{17)}$; however, our present study observed that the initial TCV could be more important than the average values during the study period; 2) although other studies defined the lower threshold for optimal TCV as $10 \mu \mathrm{g} / \mathrm{mL},{ }^{9-11)}$ we found that the ratio to achieve the clinical response was comparable between patients with initial $\mathrm{TCV}$ of $5-10$ and $\geq 10 \mu \mathrm{g} / \mathrm{mL}$; 3) the mortality rate in our study cohort was lower than the value shown in the previous study, ${ }^{11)}$ suggesting that patients included in this study might have mild or moderate bacteremia; 4) we defined the response to treatment as the resolution of several clinical signs, but did not assess microbiologic outcome. Although there were several important limitations, the present results suggested that the threshold for the target TCV could be lower than $10 \mu \mathrm{g} / \mathrm{mL}$ in pediatrics.

For adult patients with infection, it has been shown that a higher ratio of patients failed vancomycin therapy who did not achieve the initial target $\mathrm{TCV}^{18)}$ Moreover, according to recent studies, the optimal TCV of $>10 \mu \mathrm{g} / \mathrm{mL}$ for MRSA infection, and $15-20 \mu \mathrm{g} / \mathrm{mL}$ for invasive infections have been recommended. ${ }^{17,19)}$ Furthermore, studies of adults have reported that a ratio of vancomycin area under the concentration curve $(A U C)$ divided by MIC (AUC/MIC) is associated with clinical and microbiological outcomes. ${ }^{20,21)}$ The previous guideline recommended the target levels of vancomycin exposure for pediatrics as levels adjusted equivalent to those of adults. ${ }^{1)}$ However, recent findings in pharmacokinetic studies indicated that the TCV to attain the target $A U C / \mathrm{MIC}$ in children could be lower than those in adults. ${ }^{22-24)}$ In addition, given that the unbound vancomycin fraction in pediatrics and neonates is significantly higher than that in adults, ${ }^{25,26)}$ and that only unbound vancomycin has the pharmacological activity, ${ }^{27)}$ the target levels of vancomycin concentrations or $A U C / \mathrm{MIC}$ would be different in pediatric and adult patients. Our results supported this hypothesis. Thus, these findings suggest a need for further studies to define the target levels of vancomycin exposure based on the pediatric-specific pharmacokinetics and pharmacodynamics.

In this study setting, the values of initial TCV in $46.7 \%$ of patients $(n=28)$ were lower than the subtherapeutic concentration of $5 \mu \mathrm{g} / \mathrm{mL}$. Similar results were observed in previous studies including pediatrics that had similar characteristics to our study population. ${ }^{28-31)}$ It was shown that the dosage of vancomycin, $40-45 \mathrm{mg} / \mathrm{kg} / \mathrm{d}$, provided initial TCV of $<5 \mu \mathrm{g} / \mathrm{mL}$ in $29.5-38.3 \%$ of children. ${ }^{28-30)}$ Our results also found that the vancomycin pharmacokinetics in pediatrics could be affected by serum albumin, eGFR, age and body weight. There were several possible explanations of this result. First, GFR, age and body weight affected the renal clearance of vancomycin. In pediatric patients, age and body weight are covariates of renal maturation, which therefore significantly affect renal clearance of vancomycin., ${ }^{5,6)}$ Second, vancomycin binds mainly to immunoglobulin A and albumin in blood, and a strong correlation between the levels of unbound vancomycin and albumin has been found. ${ }^{32)}$ Therefore, the variability in serum albumin concentrations would result in the variability in the unbound vancomycin concentration, the clearance, or distribution of vancomycin in pediatric patients. In fact, several studies have identified serum albumin as a covariate of vancomycin clearance in neonates ${ }^{33)}$ and the volume of vancomycin distribution in children. ${ }^{34)}$ Future pharmacokinetic analysis will be informative to provide optical dosing regimen for critically ill pediatrics.

There are additional limitations to this study. First, this study had a limited sample-size, which makes it difficult to examine the effects of potential confounders and sub-group analysis. Second, since this was a retrospective and non-randomized observational investigation, various unmeasured confounders may have resulted in a bias-derived outcome. When we repeated the analyses including only patients infected with MRSA or MRCNS, the effect of TCV on the clinical response was attenuated, suggesting that the effect of TCV could be overestimated in this study. Third, we did not assess the microbiological outcomes. Fourth, we could not obtain the data on $A U C$ and unbound fraction of vancomycin. Therefore, the effect of vancomycin exposure could be incorrectly estimated.

Although this study had factors limiting a more concrete conclusion, the results suggested that the initial trough concentration of vancomycin was clinically important in achieving better outcomes in pediatric patients.

Acknowledgment This work was supported by Japanese Society for the Promotion of Science (JSPS).

Conflict of Interest The authors declare no conflict of interest.

\section{REFERENCES}

1) Liu C, Bayer A, Cosgrove SE, Daum RS, Fridkin SK, Gorwitz RJ, Kaplan SL, Karchmer AW, Levine DP, Murray BEJ, J Rybak M, Talan DA, Chambers HF. Clinical practice guidelines by the infectious diseases society of america for the treatment of methicillinresistant Staphylococcus aureus infections in adults and children. 
Clin. Infect. Dis., 52, e18-e55 (2011).

2) Yasuhara M, Iga T, Zenda H, Okumura K, Oguma T, Yano Y, Hori R. Population pharmacokinetics of vancomycin in Japanese pediatric patients. Ther. Drug Monit., 20, 612-618 (1998).

3) Monteiro JF, Hahn SR, Gonçalves J, Fresco P. Vancomycin therapeutic drug monitoring and population pharmacokinetic models in special patient subpopulations. Pharmacol. Res. Perspect., 6, e00420 (2018).

4) Rybak MJ, Le J, Lodise TP, Levine DP, Bradley JS, Liu C, Mueller BA, Pai MP, Wong-Beringer A, Rotschafer JC, Rodvold KA, Maples HD, Lomaestro BM. Executive summary: therapeutic monitoring of vancomycin for serious methicillin-resistant Staphylococcus aureus infections: a revised consensus guideline and review of the American Society of Health-System Pharmacists, the Infectious Diseases Society of America, the Pediatric Infectious Diseases Society, and the Society of Infectious Diseases Pharmacists. Pharmacotherapy, 40, 363-367 (2020)

5) McKamy S, Hernandez E, Jahng M, Moriwaki T, Deveikis A, Le J. Incidence and risk factors influencing the development of vancomycin nephrotoxicity in children. J. Pediatr., 158, 422-426 (2011).

6) Ragab AR, Al-Mazroua MK, Al-Harony MA. Incidence and predisposing factors of vancomycin-induced nephrotoxicity in children. Infect. Dis. Ther., 2, 37-46 (2013).

7) Woldu H, Guglielmo BJ. Incidence and risk factors for vancomycin nephrotoxicity in acutely ill pediatric patients. J. Pharm. Technol., 34, 9-16 (2018).

8) Moffett BS, Morris J, Kam C, Galati M, Dutta A, Akcan-Arikan A. Vancomycin associated acute kidney injury in pediatric patients. PLOS ONE, 13, e0202439 (2018).

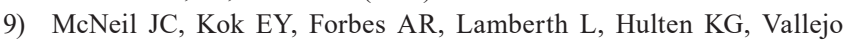
JG, Mason EO, Kaplan SL. Healthcare-associated Staphylococcus aureus bacteremia in children: evidence for reverse vancomycin creep and impact of vancomycin trough values on outcome. Pediatr. Infect. Dis. J., 35, 263-268 (2016).

10) McNeil JC, Kaplan SL, Vallejo JG. The influence of the route of antibiotic administration, methicillin susceptibility, vancomycin duration and serum trough concentration on outcomes of pediatric Staphylococcus aureus bacteremic osteoarticular infection. Pediatr. Infect. Dis. J., 36, 572-577 (2017).

11) Yoo RN, Kim SH, Lee J. Impact of initial vancomycin trough concentration on clinical and microbiological outcomes of methicillinresistant Staphylococcus aureus bacteremia in children. J. Korean Med. Sci., 32, 22-28 (2017).

12) Rainkie D, Ensom MH, Carr R. Pediatric assessment of vancomycin empiric dosing (PAVED): a retrospective review. Paediatr. Drugs, 17, 245-253 (2015).

13) Eiland LS, English TM, Eiland EH 3rd. Assessment of vancomycin dosing and subsequent serum concentrations in pediatric patients. Ann. Pharmacother., 45, 582-589 (2011).

14) Jaksic B, Martinelli G, Perez-Oteyza J, Hartman CS, Leonard LB, Tack KJ. Efficacy and safety of linezolid compared with vancomycin in a randomized, double-blind study of febrile neutropenic patients with cancer. Clin. Infect. Dis., 42, 597-607 (2006)

15) Schwartz GJ, Haycock GB, Edelmann CM Jr, Spitzer A. A simple estimate of glomerular filtration rate in children derived from body length and plasma creatinine. Pediatrics, 58, 259-263 (1976).

16) Brion LP, Fleischman AR, McCarton C, Schwartz GJ. A simple estimate of glomerular filtration rate in low birth weight infants during the first year of life: noninvasive assessment of body composition and growth. J. Pediatr., 109, 698-707 (1986).

17) Wei WX, Qin XL, Cheng DH, Lu H, Liu TT. Retrospective analysis of vancomycin treatment outcomes in Chinese paediatric patients with suspected Gram-positive infection. J. Clin. Pharm. Ther., 41, 650-656 (2016).

18) Kullar R, Davis SL, Levine DP, Rybak MJ. Impact of vancomycin exposure on outcomes in patients with methicillin-resistant Staphy- lococcus aureus bacteremia: support for consensus guidelines suggested targets. Clin. Infect. Dis., 52, 975-981 (2011).

19) Rybak MJ, Lomaestro BM, Rotschafer JC, Moellering RC, Craig WA, Billeter M, Dalovisio JR, Levine DP. Vancomycin therapeutic guidelines: a summary of consensus recommendations from the infectious diseases Society of America, the American Society of Health-System Pharmacists, and the Society of Infectious Diseases Pharmacists. Clin. Infect. Dis., 49, 325-327 (2009).

20) Moise-Broder PA, Forrest A, Birmingham MC, Schentag JJ. Pharmacodynamics of vancomycin and other antimicrobials in patients with Staphylococcus aureus lower respiratory tract infections. Clin. Pharmacokinet., 43, 925-942 (2004).

21) Lodise TP, Drusano GL, Zasowski E, Dihmess A, Lazariu V, Cosler L, McNutt LA. Vancomycin exposure in patients with methicillinresistant Staphylococcus aureus bloodstream infections: how much is enough? Clin. Infect. Dis., 59, 666-675 (2014).

22) De Cock PA, Desmet S, De Jaeger A, Biarent D, Dhont E, Herck I, Vens D, Colman S, Stove V, Commeyne S, Vande Walle J, De Paepe P. Impact of vancomycin protein binding on target attainment in critically ill children: back to the drawing board? J. Antimicrob. Chemother, 72, 801-804 (2017).

23) Emoto C, Johnson TN, McPhail BT, Vinks AA, Fukuda T. Using a vancomycin PBPK model in special populations to elucidate casebased clinical PK observations. CPT Pharmacometrics. Syst. Pharmacol., 7, 237-250 (2018).

24) Issaranggoon Na Ayuthaya S, Katip W, Oberdorfer P, Lucksiri A. Correlation of the vancomycin 24-h area under the concentrationtime curve $\left(\mathrm{AUC}_{24}\right)$ and trough serum concentration in children with severe infection: a clinical pharmacokinetic study. Int. J. Infect. Dis., 92, 151-159 (2020).

25) Oyaert M, Spriet I, Allegaert K, Smits A, Vanstraelen K, Peersman N, Wauters J, Verhaegen J, Vermeersch P, Pauwels S. Factors impacting unbound vancomycin concentrations in different patient populations. Antimicrob. Agents Chemother., 59, 7073-7079 (2015).

26) Smits A, Pauwels S, Oyaert M, Peersman N, Spriet I, Saegeman V, Allegaert K. Factors impacting unbound vancomycin concentrations in neonates and young infants. Eur. J. Clin. Microbiol. Infect. Dis., 37, 1503-1510 (2018)

27) Nielsen EI, Cars O, Friberg LE. Pharmacokinetic/pharmacodynamic (PK/PD) indices of antibiotics predicted by a semimechanistic PKPD model: a step toward model-based dose optimization. Antimicrob. Agents Chemother., 55, 4619-4630 (2011).

28) Kim DI, Im MS, Choi JH, Lee J, Choi EH, Lee HJ. Therapeutic monitoring of vancomycin according to initial dosing regimen in pediatric patients. Korean J. Pediatr., 53, 1000-1005 (2010).

29) Frymoyer A, Guglielmo BJ, Wilson SD, Scarpace SB, Benet LZ, Hersh AL. Impact of a hospitalwide increase in empiric pediatric vancomycin dosing on initial trough concentrations. Pharmacotherapy, 31, 871-876 (2011).

30) Madigan T, Sieve RM, Graner KK, Banerjee R. The effect of age and weight on vancomycin serum trough concentrations in pediatric patients. Pharmacotherapy, 33, 1264-1272 (2013).

31) Miloslavsky M, Galler MF, Moawad I, Actis J, Cummings BM, El Saleeby CM. The impact of pediatric-specific vancomycin dosing guidelines: a quality improvement initiative. Pediatrics, 139, e20162423 (2017)

32) Sun H, Maderazo EG, Krusell AR. Serum protein-binding characteristics of vancomycin. Antimicrob. Agents Chemother., 37, $1132-1136$ (1993)

33) Kim J, Walker SA, Iaboni DC, Walker SE, Elligsen M, Dunn MS, Allen VG, Simor A. Determination of vancomycin pharmacokinetics in neonates to develop practical initial dosing recommendations. Antimicrob. Agents Chemother., 58, 2830-2840 (2014).

34) Moffett BS, Morris J, Galati M, Munoz F, Arikan AA. Population pharmacokinetics of vancomycin in pediatric extracorporeal membrane oxygenation. Pediatr. Crit. Care Med., 19, 973-980 (2018). 